\title{
Benefits of the on-line healthcare services
}

\author{
Viktoriia Vovk $^{1^{*}}$ and Agnieszka Kister $^{2}$ \\ ${ }^{1}$ Stanisław Staszic University of Applied Sciences in Piła, Department of Economics, 64-920 Piła, \\ Poland \\ ${ }^{2}$ Maria Curie-Sklodowska University in Lublin, Department of Marketing, 20-031 Lublin, Poland
}

\begin{abstract}
A business model is a key tool for companies and their employees to achieve market success. It can be used by healthcare providers, though this is not a common practice. While the number of publications about business models is growing, there is no universal description of a model which can be used by hospitals. The purpose of this article is to present a new business model on the healthcare market, launching of which will be accompanied by an adjustment of the value linkage and aims to generate a sustainable competitive advantage. This proposal for a business model is based on the analysis of business models available in the literature for healthcare providers and of business models for service companies. The business model proposed serves as a main key to achieving market success by entities and their employees. The healthcare providers delivering medical services through digital technologies improve communication between doctors and patients, employees of the healthcare services and stakeholders. These technologies increase patients' quality of life and have a special meaning to increase their overall health. The digital business model provides increased values to the patients which manifests itself in service reliability information and customer focus.
\end{abstract}

Keywords: business model, healthcare services, digital health, patient satisfaction, healthcare technologies

\section{Introduction}

The COVID-19 pandemic has accelerated changes in how healthcare providers operate. It has made information technology even more useful, if not essential, for treating patients and providing remote healthcare services. Technological advancements have changed how these services are provided, and have brought a number of benefits. However, this has also had some negative consequences, including the growing costs of healthcare, and is affecting the satisfaction of patients, who are the "recipients" of healthcare services, including those provided on a remote basis. With new technology, patients have more influence over their choice of service provider, or the healthcare service itself. Information on business models is becoming the source of data for patients interested in ways of delivering value. Business models, as well as their functioning and development in healthcare, have not been thoroughly explored in the literature, and this study aims to close this gap. It relies on the literature

* Corresponding author: viktoria.vovk@puss.pila.pl 
review. Its hypothesis is that corporate business models can be adjusted for organisations providing healthcare services if specific segments are identified.

The purpose of this article is to present a new business model on the healthcare market, launching of which will be accompanied by an adjustment of the value linkage and aims to generate a sustainable competitive advantage. This proposal for a business model is based on the analysis of business models available in the literature for healthcare providers and of business models for service companies.

Business models continue to enjoy great popularity. They are employed in many scientific disciplines and can involve e-business, information systems, policies, and management [1, 2].

Clear reasons to further explore this area included companies' interest in becoming more competitive, increasing their profits by breaking down elements of business operations, and a desire to present ways of creating value for both clients and owners [3, 4]. Given the subject matter of this study, an important reason was the need to show how value is created for patients and for owners as value-creating entities. The latter are interested in observing the rules of the reasonable use of public funds and in increasing their funds.

In practice, business models help businesses solve their strategy management problems and strategically reorient themselves. Having critically analysed the literature on the subject [5-7], DaSilva and Trkman argue that the role of business models in theory has not been sufficiently explained. While some studies [8] have investigated certain aspects of business models, no clear role of business models has been identified in theory or in practice. It is also important to note that the nature of such models has not been identified for the businesses which rely on modern distribution channels. The development of business models has been influenced by the Internet and information technology. With the new technology, clients can learn about new products or services and are notified about the plans of organisations and about any new value which is being delivered. Digitisation has also led to shorter distribution and promotion chains, which influences client satisfaction considerably.

New digital technology and environments are contributing to the effectiveness of healthcare systems, and, in particular, the growing digitisation of healthcare is helping to more accurately identify patients' needs. Moreover, all this supports patient records, service planning and recording, and the performance of activities which connect healthcare providers to their stakeholders. With this growing complexity, the knowledge distributed among staff, patients, and external clients needs to be consolidated.

\section{Literature Review}

P. Timmers described a business model as an architecture for products, services and information flows, including a profile of the various business players and their roles; an analysis of the potential benefits for a range of business players; and a description of the sources of revenues. He believed that analysing the value chain was the basis for identifying a business model architecture [9]. In the literature, there are two clearly distinct approaches to defining this term: one in which a business model is a tool for generating revenue, and another in which the model is perceived as a way to deliver value [10].

Business models can be considered as templates for business operations, ways of delivering value to stakeholders, and relationships on the product and service market [11]. A. Osterwalder and Y. Pigneur have a similar perception of a business model, arguing that it describes the rationale of how an organisation creates, delivers, and captures value [12]; and similar definitions are provided by other scholars $[13,14]$.

The essence of a business model is also explained by the argument that such a model describes how a business operates by addressing the following questions: Who are our clients? What do they value? How do you deliver value to clients at a reasonable cost [15]? 
Research on business models also focuses on the relationships among the stakeholders of the relevant organisations. This has been studied by P. Weill and M.R. Vitale, who analysed business models of companies operating in the digital space. They noted that these relationships determine the flow of products, information, and money. They also examined the benefits for stakeholders [16].

The business model developed by P. Weill and M. R. Vitale comprises three elements:

- entities which develop specific business relationships, including clients, subcontractors, and suppliers;

- the flow of products, information, and money;

- benefits enjoyed by individual entities encompassed by the business model, including sales revenue.

Business models have been analysed by M. Morris, M. Schindehutte, and J. Allen. Out of 30 definitions of business models, they identified three aspects related to decisions made in companies, while also explaining model definitions - financial, operational, and strategic. In financial terms, a business model describes how a company generates profit. In operational terms, the model is about internal processes which help the company create value, and about the decisions related to the architecture and configuration of such processes. And in strategic terms, it is about the company's competitive position, cooperation with other companies and institutions, its growth capacity, making decisions concerning its relationships with stakeholders and value-building [6].

In the framework of the business model described by its authors, A. Osterwalder and Y. Pigneur, as the Business Model Canvas (BMC), the company creates value for its clients and uses this value to generate profit. The model has the form of a template with nine elements, which include the following: partner network, key activities, key resources, value propositions, customer relationships, customer segments, channels, cost structure, and revenue streams [17]. It can be used by a company to enhance its strategy and adjust the value delivered to its clients [18]. All elements can be assigned to four main fields as business operations, namely finance (costs and revenues), infrastructure, products, and clients. The analysis of the revenue structure shows the value of money generated from each market segment [12]. The structure of costs reflects the expenditures associated with the business. Generating and delivering added value to clients creates costs. A company can focus on reducing costs, or operate a business in which the level of costs is immaterial as long as such operations lead to a greater value. For organisations such as public hospitals, the end in itself is to deliver value, and the level of costs is not so important.

In case of healthcare, the business model requires modifications. In Finland, Heikkilä et al. [19] suggested a modification of this kind for the digital healthcare system. Their model includes seven key components: key partnerships, key activities, value \& services, customer relationships, customer segments, cost structure and revenue structure. The scientists emphasize that their model is based on two key customer segments, i.e., patients and companies that have contracts with healthcare providers for professional healthcare for their employees. However, the authors of this research believe that the business model developed is not comprehensive enough, as it does not include all stakeholders among consumers.

\section{Materials and methods}

This study had several stages. Stage one was the analysis of the literature on business models described from the healthcare providers' point of view. Stage two identified business models which could be used as role models for hospitals. It identified the advantages and disadvantages of such models. Stage three developed a business model for hospitals. It identified potential areas which, compared to business models for commercial organisations, were not sufficiently described. 
The study is based on a systematic literature review and a thematic analysis of 46 in-depth interviews. The overall objective of the research is to understand the essence of digital healthcare and the specific features of using business models for different sectors. The study used the Scopus-indexed data publications issued from 2001 till 2021 for the synthesis of the original research.

The given study follows systematisation principles. The authors use system approach and scientific method while determining the major advantages of using digital health and outlining the issues related to the functioning of modern hospitals. The study used modelling methods while developing relationships between patients and medical staff, pharmaceutical industry and insurance companies. Comparison methods, grouping, deductive reasoning, analytical methods helped to determine the essence of the relationship among patients, physicians, pharmacists, and insurers, as well as to identify the things they have in common. Graphical methods helped to illustrate the results of the study.

\section{Results and discussion}

The World Health Organization has praised digital health or digital medicine, as, thanks to information and communication technologies (ICTs), it can provide safe and cost-effective healthcare services to the poor, and mobile health (mHealth) will play a significant role in it [20].

Scientists believe that mHealth services and mHealth interventions of any kind have some therapeutic potential only for particular diseases, where lifestyle changes and selfmanagement of chronic diseases are crucial to advance outcomes. At the same time, it remains unclear whether the widespread use of ICTs truly improves clinical outcomes [2123]. Nevertheless, digital health actively enters everyday life around the world.

The key advantages of using digital health include the following:

- ICTs can soundly replace staff, who are the link between patients and physicians;

- the use of digital health interventions can solve a significant number of medical issues; it will reduce the workload in hospitals and increase the role of physicians in preventive care;

- digital technologies can reduce the costs of business model participants and increase their productivity;

- interaction between the Internet of Things (IoT) and healthcare takes place in 4 seconds thanks to hardware platforms, portable devices, network technologies, and cloud platforms [24];

- ICTs can facilitate the access of healthcare professionals to systematised data regarding patients' diseases and treatment history files;

- the use of devices connected to cloud platforms allows processing huge amounts of data needed for diagnostic and prognostic purposes, etc.

Minh Nguyen Dang Tuan, Nhan Nguyen Thanh and Loc Le Tuan [25] are proactive in terms of supporting digital health. The scientists view digital health as a next-generation business model that has four dimensions: decision-making promptness; trust and accountability; responsibility and competence of the workforce. The scholars believe that the IoT use will open new business opportunities.

Nowadays, it is particularly important to develop a clear business model that would advance strong links between patients and physicians and activate intensive marketing to promote online medical doctor consultations. Nonetheless, at present the commitment of medical doctors leaves room for improvement, hence the quality of medical care is nowhere near the required level, and, therefore, there is patient dissatisfaction and lack of strong links among the business model's individual components [26]. Moreover, the specific feature of the business model in healthcare is that in case of medical services, unlike all others, there is 
a fairly low tolerance of patients to malpractice, which is justified by the value of human life. In this regard, Ndubisi $[27,28]$ identifies three crucial criteria for patient satisfaction:

1) care reliability, which is revealed in the fact that, since medical services are quite difficult to standardise for their consistent implementation, it is extremely important to establish cooperation among physicians, patients and pharmacies, who have to cooperate every time and interact with each other in order to achieve the best level of care reliability. It is essential to create a channel that will ensure that physicians and pharmacies take good care of patients;

2) information reliability, which involves the availability of accurate and timely prognostic data that will prevent outbreaks of diseases and increase patients' real-time awareness of their health;

3) advanced or less briefly anticipatory conflict resolution, which can increase customer satisfaction. In this situation, researchers view customer focus as a way to create excellent value for patients, their families and their immediate environment. It is vital to understand that if patients benefit more from their treatment, they will tend to attract more new patients through both overt and covert self-promotion of their health. The quality concept postulates are reflected in the awareness of healthcare professionals of their mission regarding the patient, which provides adequate understanding of target customers, open-mindedness, vigilance to differences, sensitivity to diverse contexts, awareness of different perspectives, focus on preventing errors, failures and other sources of conflict.

In order to meet the requirements of increasingly challenging healthcare environment and improve the quality, patient treatment needs to correspond to modern conditions. Smart healthcare and the use of intelligent technologies in healthcare largely facilitate this process, as these technologies are based on improving the quality of essential everyday decisions. New technologies are able to make the healthcare system more reliable and complete, providing integration with existing systems that are critical to the proper functioning of the hospital. It should be emphasised that business models play a significant role in this transformation.

Carefully designed business models can be successfully used in order to meet the needs of patients. Many scientists believe that business models provide opportunities to accelerate progress in attaining sustainable development [29, 30]. They describe ways to create and capture values [31,32], provide competitive advantages, demonstrate the value of business with comprehensive goals for customers and society as a whole [33] and give an idea of how business works [34].

The initial step, which is required to develop an effective business model for healthcare entities, is to determine its configuration. A business model configuration is a design or arrangement of appropriately selected business model elements, necessary to deliver value proposition, which ensure that the value of the organisation grows to its highest potential. The key components of the business model for healthcare entities should include patients, medical staff, regardless of their affiliation, the pharmaceutical industry and insurance companies (Figure 1). All these key business model components interact through an electronic platform that connects them via online applications. 


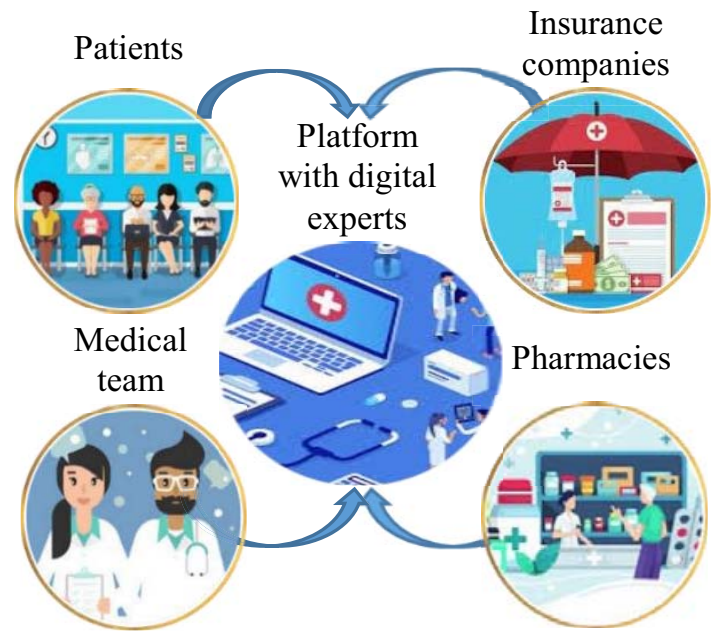

Figure 1. A business model of digital health as service Sources: developed by the authors.

Within the framework of the suggested business model, apart from communicating with physicians regarding their diseases, patients (the firth component of the business model) also can use equipment 'twenty-four to seven' to monitor their health. Such approach is particularly important for patients with chronic diseases, which allows them to accumulate data on their own devices (smartphones, watches, etc.), send the data to the cloud and provide access to physicians for examination. There are also applications where one can conduct clinical research at home, send the results simultaneously to physicians and patients, and in case of an anomaly to further inform medical doctors and even family members about the emergency [25]. The significance of such applications lies in the possibility of providing medical care in real time.

The most popular global categories of digital health in 2020 included telemedicine, data analytics, mHealth apps, clinical decision support, practice management solutions, wearable sensors, wellness, healthcare booking, social health network (Figure 2).

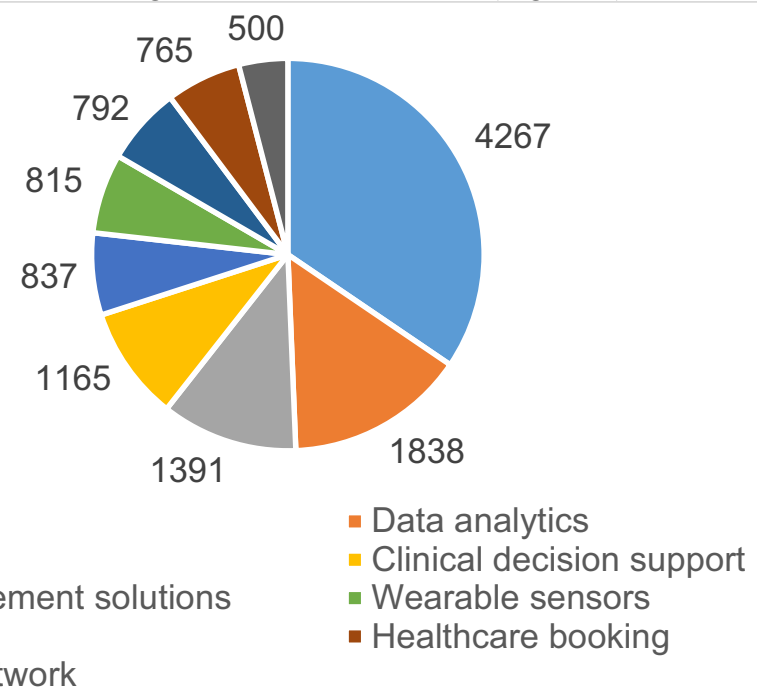

Figure 2. Top Funded Digital Health Categories Worldwide in 2020, million U.S. dollars Sources: developed by the authors based on [35]. 
According to Statista surveys, during 2020, the aforementioned categories were the top funded ones worldwide. In total, more than $\$ 4.2$ billion was allocated to telemedicine during this period, making it one of the most funded categories. During the first quarter of 2021 alone, 3,099 medical applications were available in Amazon Appstore, which is 4.27\% higher than in the previous quarter. Apparently, the COVID-19 pandemic had no small share in facilitating this growth as in January 2020 it caused a worldwide growth in the number of medical apps downloaded by $65 \%$ compared to the 'peak' month for the COVID-19 crisis [36].

In addition to mobile apps, patient digitization should also include health games (with a focus on health education and/or behaviour change), portable digital devices (sensors, trackers, etc.), and social media (getting general health information). The relevant studies show that middle-aged and specifically young people demonstrate a high level of active participation and satisfaction with the use of various clinical preventive care services, in particular those relating to physical activity, weight loss, addiction recovery (sobriety \& addiction apps), mental and sexual health [37-40]. Such features as exchanging messages aiming to get support from friends and peers, achieving goals set in apps, updating information about the users' own progress and failures, uploading photos and videos not only add motivation, but also become trendy among more and more people.

The positive digitalization aspect for patients is that they can become more aware of the healthcare system and, thus, take more responsibility for their own health and disease management [41]. Digitization also simplifies finding hospitals and medical doctors for patients, as they can take into account their ratings, distance from their respective location (if they want to make an in-person appointment), as well as available dates and times of appointments. Healthcare entities conduct patient surveys aiming to establish and analyse proper relationships between patients and clinics. The patients fill out questionnaires, which are further analysed on the likelihood of whether a patient will recommend a healthcare provider to other people. The noted information is imperative not only as an assessment of patient satisfaction, but also as a basis for enhancing the quality of medical services.

Health management technologies are becoming more accessible to the public and it is no surprise that physicians (the second element of the business model) see significant potential in using these platforms to expand healthcare delivery and increase patient interaction. The increase in the use of digital services has reduced the need for in-person consultations, which earlier used to be an absolute must. Digital medicine allows physicians to consult via video conferencing, send photos of unhealthy body parts (if a medical condition requires it), and receive electronic prescriptions and recommendations for further treatment. In case of emergency, the recovery of data about patient's disease is usually slow for traditional treatment. Furthermore, in case of specialised medical care and treatment, data transfer from one specialist to another one takes a long time. Digitizing the results of the appointment allows both accumulating data on the history of the patient's disease and quickly recalling the patient's condition, previous treatments, so that the consulting physician can pass this information to other primary care providers (PCPs) or specialists who will continue treatment. In fact, physicians obtain a channel of communication with patients in order to monitor their health and the results of their treatment.

The given approach changes not just the way of treatment, first and foremost, it changes the entire way of thinking about the treatment process. Patients tend not to fully trust physicians; however, their trust can increase significantly when, after examination and treatment, they can monitor their health on a daily basis via their usual mobile apps and digital mobile devices. Moreover, the communicative value increases due to regular online counselling, which in real time allows a consulting physician to adjust the prescribed treatment depending on the body's response to medication and manipulations. 
Digital medicine makes it possible to flexibly combine offline and online technologies. In its turn, this flexibility allows physicians to get additional work with a competitive salary, while increasing their own digital rating and getting more patients into their practice. In the traditional healthcare system, physicians work under high pressure [25]. Low salaries in public hospitals and the attachment of patients to a general practitioner basing on their residence create an uneven burden on physicians. The issue of private clinics is often the determination of a standard for the number of patients admitted and/or the volume of services provided in monetary terms. The noted approach demotivates physicians to improve the quality of services provided and to look for a personalised approach to patient care. At the same time, not only patients are personally interested in intelligent service systems. These systems also garner attention of young professionals who have the desire and ability to work intensively on their professional development.

Many countries face a number of problems associated with the operation of modern clinics and hospitals. These include, but are not limited to, the following issues:

- a lack of funds to invest in infrastructure, software, independent databases, regular software updates and adjustments;

- an insufficient government support for the appropriate implementation of programmes or strategies in the field of medicine and healthcare modernisation through the use of ICTs to meet social needs;

- the excessive number of patients or occupied hospital beds due to the lack of medical advice and preventive care, as well as insufficient qualifications of medical doctors that leads to inadequate medical care, which, in its turn, is also one of the reasons for the growing number of patients $[19,42]$. The overload of medical staff puts a significant pressure on clinics and hospitals.

In this context, the implementation of start-ups in the field of healthcare is extremely important.

The third element of the digital medicine business model is pharmacies (Figure 1). Highquality medical service includes not only medical advice and treatment, but also the use of medication and medical equipment. Physicians, patients and pharmacies have to work together in order to ensure the best results, i.e., getting a healthy patient satisfied with the medical care. The distinctiveness of pharmaceuticals is that this sector must constantly respond to epidemics and the infinite number of diseases. Without a systematic supply of medicines and medical equipment, physicians will not be able to provide adequate medical care.

In the traditional healthcare system, pharmacies often play the role of consultants as pharmacists assist and give advice to patients regarding their medication needs. However, the patients in this case lack responsibility and conscientiousness because they expose their health to the potential risk as a result of such self-medication. Obtaining an e-prescription would simplify the task of obtaining appropriate medicines and would also save a lot of time on obtaining these medications. Today, many pharmacies actively use their websites to sell online and it significantly speeds up customer service. Nevertheless, modern business models foresee the possibility of obtaining medicines without the participation of patients. A medical consultation digitized by a physician automatically sends the request to the pharmacy for a required medication.

Another problem of a modern pharmacy lies in a lack of organic relationships with physicians and clinics/hospitals [25]. Hospital pharmacies tend to be overcrowded, while other pharmacies are not in such a high demand. Redistributing the customer base via digital medicine tools would improve the relationship between pharmacies and manufacturing sites. Digitization of prescriptions allows systematisation of information on various diseases, including seasonal ones, and timely and fully adjustment of production according to the needs of patients. It also reduces the cost of medications by reducing the supply chain. Both patients 
and society would benefit from this. Patients would be able to consult physicians regularly and receive medication promptly, while society would be also able to simplify preventing and controlling obvious diseases thanks to prognostic and preventive information obtained from the digital system.

Facilitating access to digital data is an imperative step in ensuring the fruitful work of pharmaceutical companies. The noted changes are visible even now. For instance, according to the data provided by Statista back in 2014, the global online pharmacy market with the ICTs available at the time was estimated to be worth some 29 billion U.S. dollars. In 2020, this figure has almost doubled, and by 2023 it may reach 128 billion dollars [43].

Within this study, the last, fourth, component of the digital medicine business model is insurance companies. The insurance sector has already largely joined the digital transformation; and the pandemic has further expanded this process. Currently, there are a lot of companies that offer ready-made solutions for companies to integrate insurance services directly into their websites or applications. Healthcare is no exception.

Rutva Safi identifies six key digital technologies that are changing the health insurance industry [44], namely:

1. Chatbots and artificial intelligence-based voice assistants to better serve customers. Their use has become quite widespread in many related industries. They enable health insurers to offer personalized, ubiquitous services to customers and bring conversational dimensions to the process of providing such services. Chatbots can process requests related to health insurance policies; additionally inform customers about the best and/or preferential options of medical care; indicate the exact price to customers, etc.

2. AR, VR and MR for interactive customer experience. Today, new innovative technologies such as augmented reality (AR), virtual reality (VR) and mixed reality (MR) can provide virtual interaction with customers, while ensuring both consumer engagement and entertainment. Customers can independently accelerate insurance claims assessment, create and use new service niches, carry out remote management of their profile and undergo cognitive training, etc.

3. Mobility solutions to extend robust customer support. Given the widespread use of smartphones by the population, insurance companies develop and constantly update customer-facing insurance apps with convenient and easily accessible services, including the following: making policy payments, making policy changes, submitting claims, getting anytime, anywhere online consultation, checking the status of an insurance claim, delivering prescription information to pharmacies in real-time and finding the nearest pharmacy covered by the insurance plan.

4. Robotic Process Automation (RPA) to automate and streamline business processes. By leveraging RPA, the health insurance service providers can streamline and automate various business processes seamlessly, including the health insurance claim management process, fraud detection, policy administration and servicing. The effectiveness of such innovations is evidenced by the rise in data processing speed, reduction in customer service error rates, reduction in health insurance claim processing expenses.

5. Cloud computing to access big data seamlessly. By migrating to the cloud health insurers can have more control over the consumer data, manage their data in new ways and run powerful analytics against claim-based data. This technology allows them to store enormous amount of data in one place and have unlimited remote access to it, have access to real-time data, speed up responses to customer inquiries and much more. Cloud technology leads to creating new mobile applications that allow customers to manage their health, make appointments with physicians, check medical history and pay bills, and coordinate all these actions with insurance companies. 
6. Other managed services for enhanced security. As insurance companies deal with a large amount of customers' personal information, they need to enforce proactive IT security to keep their accumulated data safe and secure.

Hence, given such opportunities, insurance companies can be a reliable support for the medical sphere. Connecting to a shared customer database empowers them to manage this shared database more quickly, boost growth and enhance customer relationships.

The platform, in which four key components are integrated and synchronised into a single system, is a key element of the business model. A centralised digital medical platform assists in organising and processing digital data based on the accepted business model. All basic data is uploaded to the central platform and processed using a set of tools that can be customised according to the user needs. Then, the processed results are stored in a centralised database together with the original data. If there is a need, all these results can be re-requested, filtered and aggregated using various methods at any time [45]. A platform with digital experts is a vital element for sharing and reusing knowledge. It simplifies querying, filtering and combining a variety of data.

The suggested four-component business model has many potential benefits, which are comprehensively described above. Nonetheless, it should be kept in mind that in order to provide AI-services in business models, one should use accurate and dynamic information about the external environment and business customers. The maturity of tools and the breadth of ICTs expand the range of opportunities for the optimal business model design. In order to gain a true value from digital services, physicians, patients, pharmacists and insurers need to develop their analytical skills [46-48]. The scholars believe that a low literacy level with regard to digital medicine is the most common barrier to introducing digital health services [49]. Consequently, there is a burning need for affordable, structured and comprehensive training of health professionals, pharmacists and insurers regarding the optimal use of technology to unveil the potential of their professional development [50]. The existing studies show that there is some interest among medical doctors, nurses, hospital administrations in the use of innovative technologies in medical practice [51], and, therefore, digital technologies will become more widespread with the simultaneous modernisation of business models in accordance with the demands and capabilities of the environment.

\section{Conclusion}

Digital transformation promises to change the way health is defined and how the impact of treatment methods on healthcare is evaluated in general. In order to ensure that these digital interventions rise to their highest potential, it is crucial to turn the focus toward the activities that are most relevant to patients and allocate resources on them.

As per Statista data, the total global mHealth market is predicted to reach over 330 billion U.S. dollars in 2025. That would be a fifteenfold increase from around 21 billion dollars in 2016. Unfortunately, such rapid growth cannot but be assessed positively, as it helps to reduce costs for hospital readmission and duration of stay, has a positive effect by reducing costs of patients' non-adherence to a treatment, doctor visits costs, prevention costs, redundant examinations and medication costs, medical trial costs, labour costs, and reducing investment in technologies [52].

The digitalization growth will definitely affect the functioning of business models. Therefore, they should be open to adjustments and corrections in accordance with the actual conditions of medical services, as well as the healthcare and insurance market behaviour. New participants may appear in the markets and existing ones may undergo modifications. Currently, it can already be seen that the process and approach people use to take care of their health and well-being is different for young, middle-aged, and elderly people. 
The research has shown that modern conditions require the active use of digital technologies in medical field. Given the development of ICTs and individual needs, the use of a comprehensive business model involving four key components (patients, medical staff, pharmaceutical industry, insurance companies) on the basis of the Internet platform becomes the focal cooperation method. The noted comprehensive interaction of patients, physicians, pharmacists and insurers will increase the volume of medical services provided and increase patient satisfaction with the services.

However, even though healthcare technologies are basically shaping the healthcare future right in front of our eyes, there should not be forgotten the existence of a number of restrictive factors, which include the following: it is hard to introduce changes due to the commitment of users to the previous traditional healthcare model; personal interest of experienced physicians in digital health may be low, as the payment for this type of counselling may also often be lower, hence in the vast majority only those physicians who have recently graduated or those who have retired agree to such work; low trust in innovations both among certain groups of medical doctors and among certain groups of patients, which complicates the construction of a business model that guarantees high quality of service over a long-term horizon; insufficient skills for supporting the services in the context of digital health; low resilience to changes in the business environment among public healthcare facilities; the need to maintain an individual approach to the treatment of individual patients; as well as the fact that the use of emerging under-analysed technological developments may have consequences that are not yet sufficiently predictable. These restrictions leave room for further research and discussion.

\section{References}

1. A. Pateli, G. Giaglis, A framework for understanding and analysing e-business models, in Bled 2003 Proceedings, 4, 330-348 (2003)

2. A-P. de Man, M. de Man, A. Stoppelenburg, The characteristics of new business models in consulting: An analysis of practice, in Academy of management proceedings, 016(1), $16812(2016)$

3. J. Brzóska, Innovations as business model boosting factor (Politechniki Śląskiej Publisher, Gliwice, 2014)

4. Y. Klapkiv, V. Vovk, L. Klapkiv, Montenegrin J. Econ., 16(3), 69-82 (2020)

5. R. Casadesus-Masanell, J.E. Ricart, Long Range Plann, 43(2-3), 195-215 (2010)

6. M. Morris, M. Schindehutte, J. Allen, J. Bus. Res., 58(6), 726-735 (2005)

7. C. Zott, R. Amit, Strateg. Manag. J., 29(1), 1-26 (2008)

8. C. Zott, R. Amit, L. Massa, J Manage, 37(4), 1019-1042 (2011)

9. P. Timmers, Electron. Mark, 8(2), 3-8 (1998)

10. J. Michalak, Theoretical Accounting Notebooks, 66(122) (2012)

11. C. Zott, R. Amit, Long Range Plann, 43(2-3), 216-226 (2010)

12. A. Osterwalder, Y. Pigneur, Business model generation: A handbook for visionaries, game changers, and challengers (John Wiley \& Sons Inc, 2010)

13. D.J. Teece, Long Range Plann, 43, 172-194 (2010)

14. A. Afuah, C.L. Tucci, Internet business models and strategies: Text and cases (McGraw Hill/Irwin, New York, 2003)

15. J. Magretta, Why business models matter. Retrieved from https://hbr.org/2002/05/whybusiness-models-matter (2002)

16. P. Weill, M.R. Vitale, Place to space - migrating to e-business models (Harvard Business Review Press, 2001)

17. T. Ver Loren van Themaat, C. S. Schutte, D. Lutters, D. Kennon, South African J. Ind. Eng., 24(3), 190-204 (2013) 
18. B. Mičieta, V. Binasova, M. Kasajova, M. Kasajova, H. Howaniec, The scientific notebooks of the higher school of humanitas: Management, 21(1), 51-64 (2020)

19. M. Heikkilä, S. Solaimani, A. Soudunsaari, M. Hakanen, L. Kuivaniemi, M. Suoranta, J. Bus. Models, 2(1), 71-88 (2014)

20. World Health Organization, Atlas of eHealth Country Profiles 2015: The Use of eHealth in Support of Universal Health Coverage. Retrieved from http://biblioteca.uoc.edu/en/resources/resource/atlas-ehealth-country-profiles-2015-useehealth-support-universal-health-coverage (2021)

21. B. Smith, J. W. Magnani, Int J Cardiol, 292, 280-282 (2019)

22. P. Krebs, D. T. Duncan, JMIR mhealth uhealth, 3(4), e4924 (2015)

23. M. S. Marcolino, J. A. Q. Oliveira, M. D'Agostino, A. L. Ribeiro, M. B. M. Alkmim, D. Novillo-Ortiz, JMIR mhealth uhealth, 6(1), e23 (2018)

24. D. Kwon, M. R. Hodkiewicz, J. Fan, T. Shibutani, M. G. Pecht, IEEE Access 4, 3659 3670 (2016)

25. M. N. D. Tuan, N. N. Thanh, L. Le Tuan, Technol Forecast Soc Change, 140, 54-68 (2019)

26. A. Kister, V. Vovk, Quality monitoring model based on analysis of medical errors. In Quality Festival, 439-450 (2014)

27. N. O. Ndubisi, J. Bus. Res., 65(4), 537-546 (2012)

28. N. O. Ndubisi, N. K. Malhotra, K. W. Chan, J Int Consum Mark, 21(1), 5-16 (2009)

29. J. Levänen, M. Hossain, T. Lyytinen, A. Hyvärinen, S. Numminen, M. Halme, Sustainability, 8(1), 4 (2016)

30. P. Bicen, W.H. Johnson, Creativity Innov. Manag. 24(2), 278-299 (2015)

31. N.J. Foss, T. Saebi, J Manage, 43(1), 200-227 (2017)

32. H. Volberda, O. Mihalache, C. Fey, A. Y. Lewin, Manag Organ Rev, 13(2), 459-462 (2017)

33. N. Abdelkafi, K. Täuscher, Organ Environ, 29(1), 74-96 (2016)

34. M. Hossain, Technol. Soc., 64, 101508 (2021)

35. Statista: Top funded digital health categories worldwide in 2020. Retrieved from https://www.statista.com/statistics/736163/top-funded-health-it-technologiesworldwide/ (2021)

36. Statista: Growth in the number of medical apps downloaded during the COVID-19 pandemic by country in 2020. Retrieved from https://www.statista.com/statistics/1181413/medical-app-downloads-growth-duringcovid-pandemic-by-country/ (2021)

37. M. A. Napolitano, S. Hayes, G. G. Bennett, A. K. Ives, G. D. Foster, Obesity, 21(1), $25-$ $31(2013)$

38. N. B. Baskerville, S. Azagba, C. Norman, K. McKeown, K. S. Brown, Nicotine Tob. Res., 18(3), 351-360 (2015)

39. D. N. Cavallo, D. F. Tate, A. V. Ries, J. D. Brown, R. F. DeVellis, A. S. Ammerman, Am J Prev Med, 43(5), 527-532 (2012)

40. R. S. Buzi, P. B. Smith, C. Barrera, J Sex Marital Ther, 41(2), 126-133 (2015)

41. C. A. Wong, F. Madanay, E. M. Ozer, S. K. Harris, M. Moore, S. O. Master, M. Moreno, E. R. Weitzman, J Adolesc Health, 67(2), S24-S33 (2020)

42. M. Heikkilä, J. Heikkilä, Collaborative business model innovation process for networked services. In International conference on electronic commerce, 133-147 (2013)

43. Statista: Digital Health (2021d). Retrieved from https://www.statista.com/outlook/dmo/digital-health/worldwide

44. R. Safi, How digital technologies are transforming the health insurance industry (2020). Retrieved from https://www.softwebsolutions.com/resources/digital-technologies-forhealth-insurance-industry.html 
45. H. M. Beek, J. Bos, A. Boztas, E. J. Eijk, R. Schramp, M. Ugen, Forensic Sci. Int.: Digit Investig, 35, 301021 (2020)

46. M. Wedel, P. K. Kannan, J. Mark., 80(6), 97-121 (2016)

47. S. Akter, S. Motamarri, U. Hani, R. Shams, M. Fernando, M. M. Babu, K. N. Shen, J. Bus. Res., 118, 177-188 (2020)

48. B. Czyżewski, J. Polcyn, A. Hnatyszyn-Dzikowska, Journal of Economics, 64(10), 973 993 (2016)

49. B. Schreiweis, M. Pobiruchin, V. Strotbaum, J. Suleder, M. Wiesner, B. Bergh, J Med Internet Res, 21(11), e14197 (2019)

50. G. Jimenez, P. Spinazze, D. Matchar, G. K. C. Huat, R. M. van der Kleij, N. H. Chavannes, J. Car, Int J Med Inform, 104260 (2020)

51. A. J. Jara, M. A. Zamora-Izquierdo, A. F. Skarmeta, J. Sel. Areas Commun., 31(9), 4765 (2013)

52. Statista: Cost drivers where mobile health will have the highest positive impact worldwide in the next five years, as of 2016. Retrieved from https://www.statista.com/statistics/625219/mobile-health-global-healthcare-costreductions/ (2021c) 